\title{
Biocontrol of Carp: The Australian Plan Does Not Stand Up to a Rational Analysis of Safety and Efficacy
}

\author{
Maxime Boutier ${ }^{1}$, Owen Donohoe ${ }^{1,2}$, R. Keller Kopf ${ }^{3}$, Paul Humphries ${ }^{3}$, Joy A. Becker ${ }^{4}$, \\ Jonathan Marshall ${ }^{5,6}$ and Alain Vanderplasschen ${ }^{1 *}$ \\ ${ }^{1}$ Department of Parasitic and Infectious Diseases, University of Liège, Liège, Belgium, ${ }^{2}$ Bioscience Research Institute, \\ Athlone Institute of Technology, Athlone, Ireland, ${ }^{3}$ School of Environmental Sciences, Institute for Land Water \& Society, \\ Charles Sturt University, Albury, NSW, Australia, ${ }^{4}$ Faculty of Science, School of Life and Environmental Sciences, The \\ University of Sydney, Camden, NSW, Australia, ${ }^{5}$ Queensland Department of Environment and Science, Water Planning \\ Ecology, Brisbane, QLD, Australia, ${ }^{6}$ Australian Rivers Institute, Griffith University, Nathan, QLD, Australia
}

Keywords: biological control, Cyprinid herpesvirus 3 (CyHV-3), safety, efficacy, risks, invasive species, ecosystem restoration

\section{THE AUSTRALIAN PLAN FOR BIOCONTROL OF INVASIVE CARP USING CYPRINID HERPESVIRUS 3}

OPEN ACCESS

Edited by:

Jean-Christophe Avarre, Institut de Recherche Pour le Développement (IRD), France

Reviewed by:

Ling Jin,

Oregon State University, United States Luis E. Escobar

Virginia Tech, United States

*Correspondence: Alain Vanderplasschen a.vdplasschen@uliege.be

Specialty section: This article was submitted to

Aquatic Microbiology,

a section of the journal

Frontiers in Microbiology

Received: 03 January 2019 Accepted: 05 April 2019 Published: 30 April 2019

Citation: Boutier M, Donohoe O, Kopf RK, Humphries P, Becker JA, Marshall J

and Vanderplasschen A (2019)

Biocontrol of Carp: The Australian Plan Does Not Stand Up to a Rational

Analysis of Safety and Efficacy.

Front. Microbiol. 10:882

doi: 10.3389/fmicb.2019.00882
Common carp (Cyprinus carpio), hereafter referred as carp, is one of the most widely cultured fish produced for food globally. It was introduced into Australia for aquaculture in the mid-nineteenth century (Lintermans, 2004). Following floods in the 1970's, carp became abundant and widespread in many Australian waterways where it has come to comprise a large proportion of the fish fauna of these ecosystems (Koehn, 2004). To reduce carp population abundance and aid native species recovery, the Australian Government is evaluating the release of cyprinid herpesvirus 3 [CyHV-3, also known as koi herpesvirus (KHV)] presumed to be absent from Australia (NCCP, 2017). CyHV-3 emerged in the mid 1990's and since that time has devastated carp production worldwide (Boutier et al., 2015). Due to its economic impact on aquaculture, the Word Organization for Animal Health requires notification when the virus is identified.

In a recent opinion letter published in Frontiers in Microbiology, McColl et al. (2018) presented a series of arguments in favor of the use of CyHV-3 as a biocontrol agent against invasive carp in Australia. Here, we summarize key scientific evidence that raises concerns about the safety and efficacy of CyHV-3 as a biocontrol agent. Our review is specifically oriented to clarify misconceptions and omissions by McColl et al. (2018). A multidisciplinary review of the proposed biocontrol plan in achieving the aims of carp control in Australia was summarized recently (Kopf et al., 2019). It suggests that a more detailed cost-benefit analysis is essential before urging the release of CyHV-3 (Kopf et al., 2019).

\section{POTENTIAL SAFETY CONCERNS ASSOCIATED WITH THE USE OF CyHV-3 AS A BIOCONTROL AGENT}

Following carp mortality caused by CyHV-3, decomposing dead fish could itself lead to undesirable environmental damage (Lighten and van Oosterhout, 2017). A detailed analysis of this indirect risk vs the potential benefits of the use of CyHV-3 is published elsewhere (Kopf et al., 2019). The virus may also cause direct deleterious effects by infection of non-target species.

Herpesviruses have mainly evolved by co-speciation with their host, leading to a narrow host range restricted to their natural host species and closely related species (Waltzek et al., 2009). Consistently, it has been demonstrated that CyHV-3 causes mortality only in common and koi carp. However, the ability of the virus to establish subclinical infection in nonnatural host species, to persist and to be transmitted from the latter to naive cohabitant 
carp has been suggested based on PCR analyses (Kempter et al., 2012; Fabian et al., 2013, 2016). The biological relevance of these data should be taken with caution as the signals observed were weak and the transmission to sentinel carp was never associated with the expression of CyHV-3 disease. The risk of CyHV-3 infecting non-target species of Australia was investigated in limited experimental conditions in a recent paper (McColl et al., 2017). Importantly, the results of that study indicate that CyHV-3 may have induced mortality in at least some native fish species [e.g. silver perch (Bidyanus bidyanus)] in Australia. McColl et al. (2017) ignored the potential role of CyHV-3 in the deaths observed (including in the groups where mortality was significantly higher in infected than in mock-infected groups) by presenting data suggesting that viral transcripts could not be detected in dead fish. The possibility of technical issues or the hypothesis that CyHV-3 could induce death in nonnatural host species through a non-replicative pathogenesis, as observed for other herpesviruses (e.g., alcelaphine herpesvirus 1) (Palmeira et al., 2013), were not addressed. For these reasons, the data published by McColl et al. (2017) cannot be used to conclusively support the safety of CyHV-3 as a biocontrol agent with regards to effects on non-target species in Australian waterways. Further experiments are still required to investigate this question.

While phylogenetic analyses demonstrate that herpesviruses have mainly evolved by co-speciation with their host, they also suggest that host-jumps have occurred on several occasions throughout evolution (Waltzek et al., 2009). The proposed biocontrol plan consisting of a continental-scale release of a fully virulent strain may represent an unprecedented scenario favoring the selection of a mutant able to infect non-natural host species.

\section{FACTORS LIKELY TO NEGATIVELY AFFECT THE EFFICACY OF CyHV-3 AS A BIOCONTROL AGENT}

\section{Natural Resistance and Fecundity of Carp}

The existence of genetic polymorphisms conferring resistance to a biocontrol agent associated with the high fecundity of the target species represent major obstacles to long-term efficacy of that biocontrol measure. While preliminary experiments performed in laboratory conditions demonstrated that at least some of the wild Australian carp are susceptible to CyHV-3 disease (McColl et al., 2017), the same study also demonstrated the existence of rather resistant subjects (associated with low mortality rates of $40 \%$ ). It has been reported that genetic polymorphisms conferring resistance to CyHV-3 exist in carp populations (Dixon et al., 2009; Rakus et al., 2009). Of note, epidemiological data suggested that the Eurasian genetic lineages of carp, from which most invasive carp in Australia have descended (Haynes et al., 2012), were largely unaffected by a previous CyHV-3 natural outbreak in Japan (Uchii et al., 2014). Furthermore, wild Australian carp can breed with goldfish (Carassius auratus) and produce viable offspring which are expected to have a high resistance to CyHV-3 disease (Kopf et al., 2019) based on studies from the northern hemisphere (Hedrick et al., 2006; Bergmann et al., 2010). Hybridization may introduce resistance alleles into carp populations. If CyHV-3 is released and acts as a selection pressure, it will inevitably induce selection for resistant individuals that will rapidly repopulate the ecosystem. Indeed, carp have an extremely high fecundity and a short generation time. Of note, a mature female carp lays around 100,000-200,000 eggs per kilogram of body weight (Swee and McCrimmon, 1966).

\section{Effect of Environment on CyHV-3 Disease}

Carp is an ectotherm, and as such its biology is highly influenced by the temperature of the water. This environmental factor has been shown to determine the outcome of CyHV-3 infection (Gilad et al., 2003) and has important consequences for biocontrol efficacy (Marshall et al., 2018; Kopf et al., 2019). CyHV-3 can cause disease (i.e., clinical signs and mortalities) at temperatures from 18 to $28^{\circ} \mathrm{C}$ (Rakus et al., 2013). At low temperatures $\left(<15^{\circ} \mathrm{C}\right)$, carp are sensitive to CyHV-3 infection but they do not express clinical signs under such conditions (Sunarto et al., 2014). Also, the adaptive immune system of carp is down regulated below $14^{\circ} \mathrm{C}$ (Bly and Clem, 1992), thus individuals infected at this temperature do not acquire a memory immune response and frequently develop disease when returned to permissive temperatures (Sunarto et al., 2014). Above $30^{\circ} \mathrm{C}$ the virus ceases to replicate and is innocuous to carp. This property has been used in aquaculture to immunize carp against the virus (Ronen et al., 2003). Healthy fingerlings are exposed to the virus by cohabitation with sick fish for 3-5 days at permissive temperature $\left(22-23^{\circ} \mathrm{C}\right)$. After that, the fish are transferred to a non-permissive water temperature $\left(\approx 30^{\circ} \mathrm{C}\right)$ for $25-30$ days, leading to arrest of viral replication and immunization of the fish.

Ectotherms lack intrinsic thermogenesis and, in most cases, control their body temperature by thermoregulatory movement behavior (Rakus et al., 2017b). In a temperature gradient, ectotherms select a species-specific range of preferred temperature which is defined as "final thermal preferendum." In response to infection or injection of exogenous pyrogens, ectotherms can increase their body temperature above this final thermal preferendum. This process occurs through behavioral regulation, which leads the animals to move to a warmer environment. This phenomenon is known as "behavioral fever" and is defined as an acute increase of the final thermal preferendum driven by pathogen infection (Evans et al., 2015; Rakus et al., 2017b). Recently, it has been demonstrated that carp infected by CyHV-3 express behavioral fever (Rakus et al., 2017a) by actively seeking warm water. The expression of behavioral fever was shown in laboratory conditions to be beneficial for infected individuals. They all controlled the infection rapidly after expressing behavioral fever, whereas fish maintained at permissive temperature died from the infection (Rakus et al., 2017a).

In combination, the data described above demonstrates the importance of temperature in the outcome of CyHV-3 disease. Whereas aquaculture activities are associated with a rather homogeneous temperature, carp in the wild are exposed to a broad range of temperatures, which could lead to immunization against CyHV-3 rather than to death. An analysis of the 
temperature variation in the Australian freshwater environment (Becker et al., 2018; Kopf et al., 2019) suggests that this key environmental parameter is likely to negatively affect the impact of CyHV-3 as a biocontrol agent.

\section{Lessons to be Learned From the Effect of CyHV-3 on Wild Carp Population}

The assumption that CyHV-3 could act as an efficient biocontrol agent against wild carp is based on the damage this virus has been causing to the aquaculture sector. However, in natural aquatic ecosystems, carp can move freely, have higher genetic diversity, patchier and lower density, and the environment is more variable and heterogeneous (e.g., water temperature) than in aquaculture ponds or under laboratory conditions (Kopf et al., 2019). Therefore, we expect the mortality of carp, following implementation of the proposed $\mathrm{CyHV}-3$ biocontrol application in the wild, to be much lower and more variable than in laboratory trials and aquaculture ponds (Becker et al., 2018). In support of our hypothesis, it is worth noting that of the few confirmed CyHV-3 carp fish kills in rivers or lakes worldwide, most have had little or no long-term detectable effect on carp abundance (Thresher et al., 2018). For example, Japanese rivers have been monitored for CyHV-3 since 2004, when the virus was associated with mass carp death in Lake Biwa. Ever since, infection has remained widespread without obvious disease outbreaks (Uchii et al., 2014). Finally, several studies have monitored the prevalence of CyHV-3 in Lake Biwa, illustrating a dichotomous nature of viral spread. While young sexually immature carp $(<35 \mathrm{~cm})$ are rarely CyHV-3 infected or seropositive, sexually mature carp $(>35 \mathrm{~cm})$ have a very high infection rate (Uchii et al., 2009). This suggests that the breeding behavior of carp promotes CyHV-3 transmission without mortality (Uchii et al., 2011). This phenomenon could be explained, in the wild, by exposure of carp to CyHV-3 during the adult age, i.e., when carp are less sensitive to the disease. Indeed, a strong age-dependent susceptibly of carp to CyHV-3 has been documented (Perelberg et al., 2003).

The observation that CyHV-3 can persist in the wild without inducing carp death suggests that the expression of the disease requires environmental co-factors. Notably, the lack of recorded CyHV-3-associated mass carp deaths in Australia may simply reflect a lack of environmental co-factors rather than the absence of the virus. A recent phylogenetic study suggested that ancestors of CyHV-3 may have infected carp populations, long before the initial outbreaks of the disease were first reported (Gao et al., 2018) and thus long before the introduction of carp in Australia (Kopf et al., 2019). This hypothesis suggests that CyHV-3 could already be present in Australia (Marshall et al., 2018) and that the environmental co-factors found there do not favor the expression of the disease.

\section{CONCLUSION}

Invasive carp expanded in Australia to their current range and relative abundance decades ago (Shearer and Mulley,
1978; Koehn, 2004). Despite political pressure, there is no environmental justification to rush the release of a viral biocontrol agent. Before continental-scale release of CyHV-3, which would be costly and irreversible, further assessments should include obtaining convincing evidence that prolonged exposure to the virus does not pose a significant risk to non-target native species especially in terms of potential selection for mutations favoring adaptation to such species. While field trials are practicable in endemic areas, they are irrational in a country thought to be free of $\mathrm{CyHV}-3$ and using conditions that cannot guarantee the confinement of the virus. Despite assertions by McColl et al. (2018) that carp biocontrol "is more than just a herpesvirus," the National Carp Control Plan has no viable plan or technology in place to prevent the immediate recovery of carp populations following potential mortality events. Indeed, an integrated carp management plan should be proposed and implemented. The Daughterless Carp Project is theoretically feasible, but there is presently no large-scale program implementing the production of broodstock or young that would be required for the release. In addition, the long-term safety and efficacy of this technology require further investigation. The authors of this opinion letter represent expertise in intermittent river ecology, aquatic ecology, epidemiology, viral pathogenesis, immunology, herpesviruses, and CyHV-3. We all support the idea that the implementation of a biocontrol measure must be based on robust scientific evidence considering the potential long-term negative effects on the native biodiversity. We do not share the opinion of McColl et al. (2016) who claim "Whatever the nature of the relationship between transmissibility and virulence, the release of CyHV-3 undoubtedly represents a unique and exciting natural experiment that will provide the first opportunity to track, in real time, the co-evolution of both the biocontrol virus and the targeted host."

\section{AUTHOR CONTRIBUTIONS}

All authors listed have made a substantial, direct and intellectual contribution to the work, and approved it for publication.

\section{FUNDING}

At the time of submission of this manuscript, none of the authors received any funding from the Australia's National Carp Control Program (NCCP).

\section{ACKNOWLEDGMENTS}

JB and JM are both members of the NCCP's independent Scientific Advisory Group, they both declare respect of confidentiality associated with their role in drafting the present manuscript. OD is a Marie Curie research fellow (European Union). 


\section{REFERENCES}

Becker, J. A., Ward, M. P., and Hick, P. M. (2018). An epidemiologic model of koi herpesvirus (KHV) biocontrol for carp in Australia. Aust. Zool. doi: 10.7882/az.2018.038. [Epub ahead of print].

Bergmann, S. M., Sadowski, J., Kielpinski, M., Bartlomiejczyk, M., Fichtner, D., Riebe, R., et al. (2010). Susceptibility of koi x crucian carp and koi x goldfish hybrids to koi herpesvirus (KHV) and the development of KHV disease (KHVD). J. Fish Dis. 33, 267-272. doi: 10.1111/j.1365-2761.2009.01127.x

Bly, J. E., and Clem, W. (1992). Temperature and teleost immune functions. Fish Shellish Immunol. 2, 159-171.

Boutier, M., Ronsmans, M., Rakus, K., Jazowiecka-Rakus, J., Vancsok, C., Morvan, L., et al. (2015). Cyprinid Herpesvirus 3: an archetype of fish alloherpesviruses. Adv. Virus Res. 93, 161-256. doi: 10.1016/bs.aivir.2015.03.001

Dixon, P. F., Joiner, C. L., Way, K., Reese, R. A., Jeney, G., and Jeney, Z. (2009). Comparison of the resistance of selected families of common carp, Cyprinus carpio L., to koi herpesvirus: preliminary study. J. Fish Dis. 32, 1035-1039. doi: 10.1111/j.1365-2761.2009.01081.x

Evans, S. S., Repasky, E. A., and Fisher, D. T. (2015). Fever and the thermal regulation of immunity: the immune system feels the heat. Nat. Rev. 15, 335-349. doi: 10.1038/nri3843

Fabian, M., Baumer, A., Adamek, M., and Steinhagen, D. (2016). Transmission of Cyprinid herpesvirus 3 by wild fish species-results from infection experiments. J. Fish Dis. 39, 625-628. doi: 10.1111/jfd.12399

Fabian, M., Baumer, A., and Steinhagen, D. (2013). Do wild fish species contribute to the transmission of koi herpesvirus to carp in hatchery ponds? J. Fish Dis. 36, 505-514. doi: 10.1111/jfd.12016

Gao, Y., Suarez, N. M., Wilkie, G. S., Dong, C., Bergmann, S., Lee, P. A., et al. (2018). Genomic and biologic comparisons of cyprinid herpesvirus 3 strains. Vet. Res. 49:40. doi: 10.1186/s13567-018-0532-z

Gilad, O., Yun, S., Adkison, M. A., Way, K., Willits, N. H., Bercovier, H., et al. (2003). Molecular comparison of isolates of an emerging fish pathogen, koi herpesvirus, and the effect of water temperature on mortality of experimentally infected koi. J. Gen. Virol. 84(Pt 10), 2661-2667. doi: 10.1099/vir.0.19323-0

Haynes, G. D., Gongora, J., Gilligan, D. M., Grewe, P., Moran, C., and Nicholas, F. W. (2012). Cryptic hybridization and introgression between invasive Cyprinid species Cyprinus carpio and Carassius auratus in Australia: implications for invasive species management. Anim. Conserv. 15, 83-94. doi: $10.1111 /$ j.1469-1795.2011.00490.x

Hedrick, R. P., Waltzek, T. B., and McDowell, T. S. (2006). Susceptibility of Koi Carp, Common Carp, Goldfish, and Goldfish $\times$ Common Carp Hybrids to Cyprinid Herpesvirus-2 and Herpesvirus-3. J. Aquat. Anim. Health 18, 26-34. doi: 10.1577/h05-028.1

Kempter, J., Kielpinski, M., Panicz, R., Sadowski, J., Myslowski, B., and Bergmann, S. M. (2012). Horizontal transmission of koi herpes virus (KHV) from potential vector species to common carp. Bull Eur Assoc Fish Pathol 32, 212-219. Available online at: https://eafp.org/download/2012-volume32/ issue_6/212-Kempter_2.pdf

Koehn, J. D. (2004). Carp (Cyprinus carpio) as a powerful invader in Australian waterways. Freshw. Biol. 49, 882-894. doi: 10.1111/j.1365-2427.2004.01232.x

Kopf, R. K., Boutier, M., Finlayson, C. M., Hodges, K., Humphries, P., King, A., et al. (2019). Biocontrol in Australia: can a carp herpesvirus (CyHV-3) deliver safe and effective ecological restoration? Biol. Invasions. doi: 10.1007/s10530-019-01967-1. [Epub ahead of print].

Lighten, J., and van Oosterhout, C. (2017). Biocontrol of common carp in Australia poses risks to biosecurity. Nat. Ecol. Evol. 1:87. doi: 10.1038/s41559-017-0087

Lintermans, M. (2004). Human-assisted dispersal of alien freshwater fish in Australia. N. Z. J. Mar. Freshw. Res. 38, 481-501. doi: $10.1080 / 00288330.2004 .9517255$

Marshall, J., Davison, A. J., Kopf, R. K., Boutier, M., Stevenson, P., and Vanderplasschen, A. (2018). Biocontrol of invasive carp: risks abound. Science 359:877. doi: 10.1126/science.aar7827

McColl, K. A., Sunarto, A., and Holmes, E. C. (2016). Cyprinid herpesvirus 3 and its evolutionary future as a biological control agent for carp in Australia. Virol. J. 13:206. doi: 10.1186/s12985-016-0666-4

McColl, K. A., Sunarto, A., and Neave, M. J. (2018). Biocontrol of carp: more than just a Herpesvirus. Front. Microbiol. 9:2288. doi: 10.3389/fmicb.2018.02288

McColl, K. A., Sunarto, A., Slater, J., Bell, K., Asmus, M., Fulton, W., et al. (2017). Cyprinid herpesvirus 3 as a potential biological control agent for carp (Cyprinus carpio) in Australia: susceptibility of non-target species. J. Fish Dis. 40, 1141-1153. doi: 10.1111/jfd.12591
NCCP (2017). The National Carp Control Plan Strategic Research and Technology Plan 2017-2019. Fisheries Research and Development Corporation, Australia.

Palmeira, L., Sorel, O., Van Campe, W., Boudry, C., Roels, S., Myster, F., et al. (2013). An essential role for gamma-herpesvirus latency-associated nuclear antigen homolog in an acute lymphoproliferative disease of cattle. Proc. Natl. Acad. Sci. U.S.A. 110, E1933-1942. doi: 10.1073/pnas. 1216531110

Perelberg, A., Smirnov, M., Hutoran, M., Diamant, A., Bejerano, Y., and Kotler, M. (2003). Epidemiological description of a new viral disease afflicting cultured Cyprinus carpio in Israel. Israeli J. Aquacult. 55, 5-12. Available online at: http:// hdl.handle.net/10524/19063

Rakus, K., Ouyang, P., Boutier, M., Ronsmans, M., Reschner, A., Vancsok, C., et al. (2013). Cyprinid herpesvirus 3: an interesting virus for applied and fundamental research. Vet. Res. 44:85. doi: 10.1186/1297-9716-44-85

Rakus, K., Ronsmans, M., Forlenza, M., Boutier, M., Piazzon, M. C., JazowieckaRakus, J., et al. (2017a). Conserved fever pathways across vertebrates: a herpesvirus expressed decoy TNF-alpha receptor delays behavioral fever in fish. Cell Host Microbe 21, 244-253. doi: 10.1016/j.chom.2017.01.010

Rakus, K., Ronsmans, M., and Vanderplasschen, A. (2017b). Behavioral fever in ectothermic vertebrates. Dev. Comp. Immunol. 66, 84-91. doi: $10.1016 /$ j.dci.2016.06.027

Rakus, K. L., Wiegertjes, G. F., Adamek, M., Siwicki, A. K., Lepa, A., and Irnazarow, I. (2009). Resistance of common carp (Cyprinus carpio L.) to Cyprinid herpesvirus-3 is influenced by major histocompatibility (MH) class II B gene polymorphism. Fish Shellfish Immunol. 26, 737-743. doi: 10.1016/j.fsi.2009.03.001

Ronen, A., Perelberg, A., Abramowitz, J., Hutoran, M., Tinman, S., Bejerano, I., et al. (2003). Efficient vaccine against the virus causing a lethal disease in cultured Cyprinus carpio. Vaccine 21, 4677-4684. doi: 10.1016/S0264-410X(03)00523-1

Shearer, K. D., and Mulley, J. C. (1978). The Introduction and Distribution of the Carp, Cyprinus carpio Linnaeus, in Australia. Mar. Freshw. Res. 29:551. doi: $10.1071 / \mathrm{mf} 9780551$

Sunarto, A., McColl, K. A., Crane, M. S., Schat, K. A., Slobedman, B., Barnes, A. C., et al. (2014). Characteristics of cyprinid herpesvirus 3 in different phases of infection: implications for disease transmission and control. Virus Res. 188, 45-53. doi: 10.1016/j.virusres.2014.03.024

Swee, U. B., and McCrimmon, H. R. (1966). Reproductive Biology of the Carp, Cyprinus carpio L., in Lake St. Lawrence, Ontario. Trans. Am. Fisheries Soc. 95, 372-380. doi: 10.1577/1548-8659(1966)95<372:rbotcc >2.0.co;2

Thresher, R. E., Allman, J., and Stremick-Thompson, L. (2018). Impacts of an invasive virus (CyHV-3) on established invasive populations of common carp (Cyprinus carpio) in North America. Biol. Invasions 20, 1703-1718. doi: 10.1007/s10530-017-1655-2

Uchii, K., Matsui, K., Iida, T., and Kawabata, Z. (2009). Distribution of the introduced cyprinid herpesvirus 3 in a wild population of common carp, Cyprinus carpio L. J. Fish Dis. 32, 857-864. doi: $10.1111 / \mathrm{j} .1365-2761.2009 .01064 . \mathrm{x}$

Uchii, K., Minamoto, T., Honjo, M. N., and Kawabata, Z. I. (2014). Seasonal reactivation enables Cyprinid herpesvirus 3 to persist in a wild host population. FEMS Microbiol. Ecol. 87, 536-542. doi: 10.1111/1574-6941. 12242

Uchii, K., Telschow, A., Minamoto, T., Yamanaka, H., Honjo, M. N., Matsui, K., et al. (2011). Transmission dynamics of an emerging infectious disease in wildlife through host reproductive cycles. ISME J. 5, 244-251. doi: 10.1038 /ismej.2010.123

Waltzek, T. B., Kelley, G. O., Alfaro, M. E., Kurobe, T., Davison, A. J., and Hedrick, R. P. (2009). Phylogenetic relationships in the family Alloherpesviridae. Dis. Aquat. Org. 84, 179-194. doi: 10.3354/dao02023

Conflict of Interest Statement: The authors declare that the research was conducted in the absence of any commercial or financial relationships that could be construed as a potential conflict of interest.

Copyright (c) 2019 Boutier, Donohoe, Kopf, Humphries, Becker, Marshall and Vanderplasschen. This is an open-access article distributed under the terms of the Creative Commons Attribution License (CC BY). The use, distribution or reproduction in other forums is permitted, provided the original author(s) and the copyright owner(s) are credited and that the original publication in this journal is cited, in accordance with accepted academic practice. No use, distribution or reproduction is permitted which does not comply with these terms. 